\title{
LOS HERRAJES DE LA SILLERÍA DEL CORO \\ Y LA LIBRERÍA GÓTICA DE LA CATEDRAL DE BARCELONA: ESTUDIO HISTÓRICO Y SECUENCIA DOCUMENTAL
}

\author{
THE CHOIR STALLS' IRONWORK AND THE GOTHIC BOOKCASE OF \\ BARCELONA CATHEDRAL: HISTORICAL STUDY AND DOCUMENTARY SEQUENCE
}

\section{Luisa Amenós Martínez* \\ Dra. en Historia del Arte y Técnico de Patrimonio Cultural}

\section{Resumen}

La Catedral de Barcelona conserva dos conjuntos muebles de singular interés para el estudio del mobiliario de época medieval: la sillería del coro y la 'librería' del denominado 'arxiu de mitja escala'. Ambos conjuntos mantienen los herrajes originales, que se caracterizan por presentar una bella y delicada decoración.

Durante mi tesis doctoral, pude localizar la secuencia constructiva de ambos muebles y documentar la ejecución de los herrajes en los libros de obra. El análisis visual de éstos, efectuado recientemente a raíz de un proyecto de catalogación, ha evidenciado los paralelismos que existen con el mobiliario medieval conservado en el monasterio de Santa María de Pedralbes (Barcelona) y su capacidad de confirmar las atribuciones estilísticas realizadas por los historiadores del arte en relación con la escultura de la sillería del coro.

Palabras clave: herrajes, mobiliario, medieval, Catedral de Barcelona, Monasterio de Pedralbes

\section{Abstract}

The Barcelona Cathedral preserves two sets of furniture with singular interest for the study of medieval period furniture: the choir stalls and the 'bookstore' of the so-called 'Arxiu de mitja escala'. Both sets maintain the original ironworks, which have a beautiful and delicate decoration. In my doctoral thesis, I located the construction sequence of both furniture and documented the execution of their iron fittings in the Llibres d'Obra ['work books'].

In 2019 , as a consequence of an heritage inventory, I was able to analyze this pieces and check their parallels with the medieval furniture of the Santa Maria de Pedralbes monastery (Barcelona) and to confirm the stylistic attributions made by art historians in relationship with the sculpture of the choir stalls.

Keywords: ironwork, furniture, medieval, Barcelona Cathedral, Pedralbes Monastery 


\section{Introducción}

El coro de la Catedral de Barcelona es uno de los pocos que permanecen en su emplazamiento original. Situado en medio de la nave central, y protegido por un muro de piedra, conserva en su interior varios elementos de mobiliario litúrgico de alto valor artístico: el sitial episcopal, el púlpito, la sillería con todos sus componentes y la cantoria, o legender, ubicada encima del trascoro.

La sillería actual, ejecutada entre fines del siglo XIV y la última década del siglo XV, está formada por dos hileras de sitiales paralelos que dibujan una planta en forma de "U", abierta al presbiterio y cerrada originalmente en el trascoro -la puerta actual parece que se abrió en el siglo XVI-.

La sillería soberana o alta, destinada a los canónigos, está formada por 62 sillas -66 en origen- y presenta una rica y variada ornamentación tallada en las misericordias, los medallones y las brazaleras. La complementan unos vistosos respaldos altos, coronados por doseles hexagonales y pináculos de tracería realizados entre fines del siglo XV y el primer cuarto del siglo XVI aunque algunos de los más próximos al presbiterio podrían datar de comienzos del siglo XV.

La sillería baja está constituida por 58 unidades que siguen la misma tipología y configuración de las anteriores, aunque carecen de respaldos y acusan una menor riqueza iconográfica. Se articulan en grupos de seis o siete sitiales, entre los cuales se dispone la gradería que da acceso a la sillería alta.

Los diversos tramos de sillas están delimitados por unas artísticas 'potencias' o mamparas realizadas en el primer cuarto del siglo XVI. Entre los sitiales de la sillería baja se disponían seis facistoles alzados sobre una tarima que hacía la función de soporte. Fueron desmontados después de la Guerra Civil y su rastro se intentó disimular construyendo nuevos asientos a manera de los antiguos, aunque los delatan el color y textura de la madera, así como los herrajes de factura industrial sin decoración. Diversos reportajes fotográficos anteriores a la Guerra Civil, permiten visualizar los facistoles y localizar su ubicación original. ${ }^{1}$ La mayoría de ellos eran de madera tallada, con decoración de tracería gótica, excepto uno de hierro forjado por Pere Riembau en 1489 (fig. 1, izq.). ${ }^{2}$ El facistol mayor del coro, emplazado en el centro del espacio, estaba coronado por una vistosa cartela -o brazo de luz- de hierro, ejecutada -o instalada-por Antoni Sureda en 1481 (fig. 1, der.). ${ }^{3}$ Ambas piezas se conservan desmontadas en los almacenes de la Catedral.

Completaban la iluminación del facistol mayor dos candelabros de pie forjados seguramente por el herrero Antoni Fabra, puesto que el 26 de agosto de 1495 cobró por "dos canalobras de ferro, que entran e hixen lo faristol major del cor, per tenir los siris a les matines". ${ }^{4}$ 


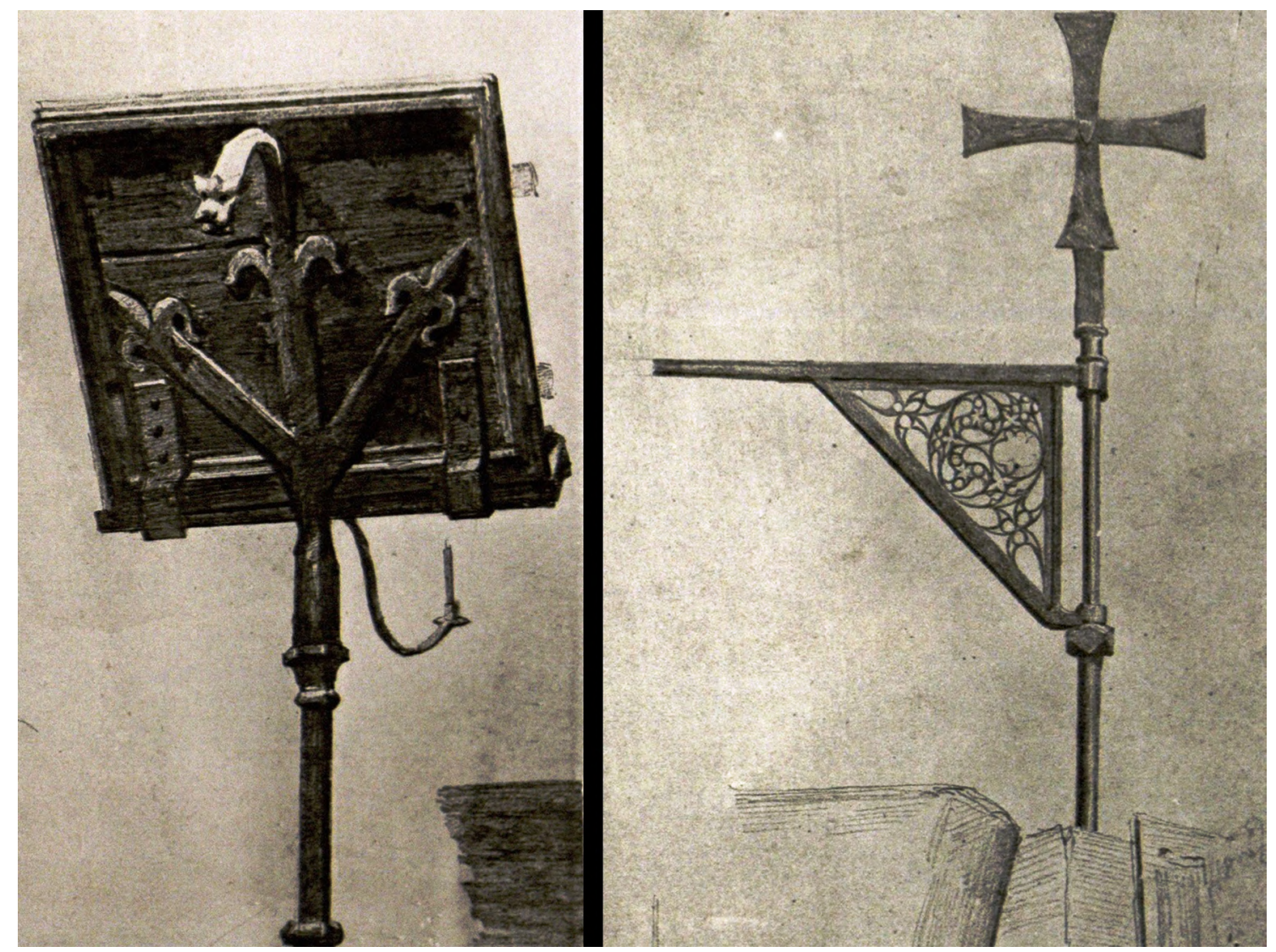

Fig. 1. Izquierda: facistol de la sillería baja del coro de la Catedral de Barcelona. Derecha: cartela, o brazo de luz, del facistol mayor. Dibujos publicados en Àlbum de detalles artísticos, 37 y 38, fig. núm. 64 y 64 bis.

\section{Los herrajes de la sillería del coro de la Catedral de Barcelona}

La sillería del coro responde a la tipología de asiento abatible con Misericordia, constituido por dos piezas independientes y articuladas con dos bisagras equidistantes encajadas en un rebajo de la madera. ${ }^{5}$ Las bisagras responden a la tipología denominada de libro, es decir, constituidas por dos palas rectangulares articuladas por el tradicional sistema de pernios y argollas. Están clavadas con clavos-remaches de sujeción, cuyos extremos opuestos -los correspondientes a las misericordias- pueden exhibir cabezas floronadas realizadas seguramente mediante la técnica de estampación con matriz. Las palas, visibles sólo cuando el asiento se encuentra bajado, presentan decoración grabada en toda su superficie a base de motivos geométricos ejecutados a punzón y organizados conforme a un diseño lineal y repetitivo. Se documentan tres diseños básicos (fig. 2):

- Tipo A: motivos punteados diminutos que ocupan la totalidad de la superfície. Este tipo de decoración se encuentra en las palas que articulan los sitiales de la Epístola y el Evangelio de la sillería alta y los del tercer tramo de la sillería baja. 
- Tipo B: medias lunas, círculos y motivos serpenteantes distribuidos longitudinalmente en hileras regulares. Decoran las palas de los sitiales situados en los dos primeros tramos de la sillería baja, tanto en el lado de la Epístola como del Evangelio. Este diseño desarrolla dos variantes sobre un mismo modelo ornamental.

- Tipo C: medias lunas y soles radiantes -o flores esquematizadas-distribuidos longitudinalmente en hileras regulares. Decoran las palas de los sitiales situados en el trascoro. Este diseño desarrolla tres variantes sobre un mismo modelo ornamental, si bien una de ellas -la $\mathrm{C}^{3}$ - se documenta en poquísimas ocasiones.

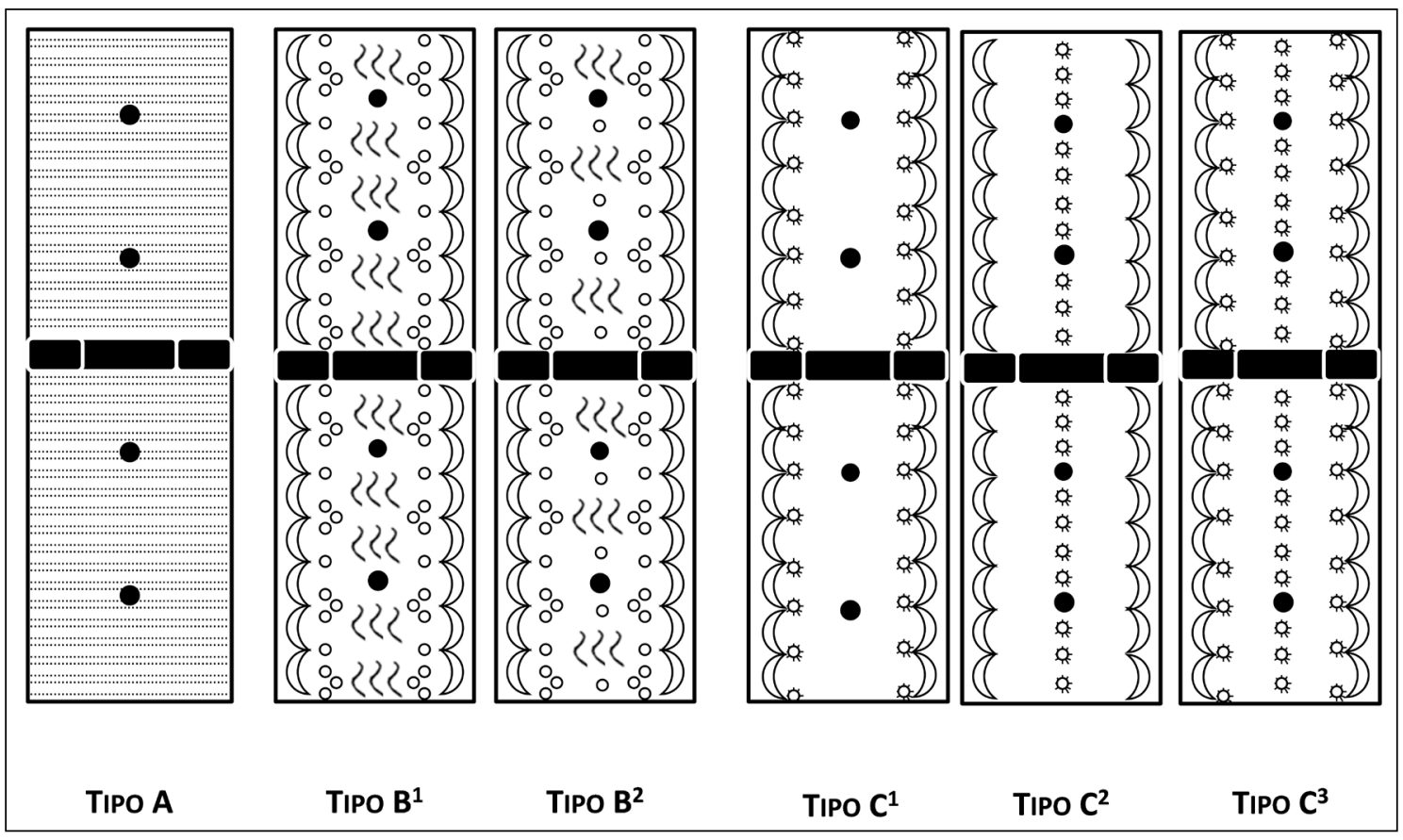

Fig. 2. Esquema de los diseños decorativos grabados en las palas de las bisagras de la sillería del coro de la Catedral de Barcelona.

Los motivos decorativos se distribuyen por sectores en el conjunto de la sillería (fig. 3). Esta sectorización responde a la lógica constructiva del conjunto, que se desarrolló de forma discontinua a lo largo de un periodo comprendido entre fines del siglo XIV y fines del siglo XV. ${ }^{6}$ Los primeros sitiales fueron ejecutados entre los años 1394 y 1399 por un equipo de artesanos dirigidos por el escultor Pere Ça Anglada. Labraron los tramos laterales de la sillería alta, es decir, las hileras de sillas paralelas al coro de San Pedro -en el lado del Evangelio-y al coro de San Juan -en el lado de la Epístola. Entre 1397 y 1399 , el herrero Bernat Major suministró los clavos y las 'galavernes' destinadas a los respaldos de los sitiales y en 1398 Pascual Tarraga proporcionó las bisagras (vid. las transcripciones documentales en el anexo). 


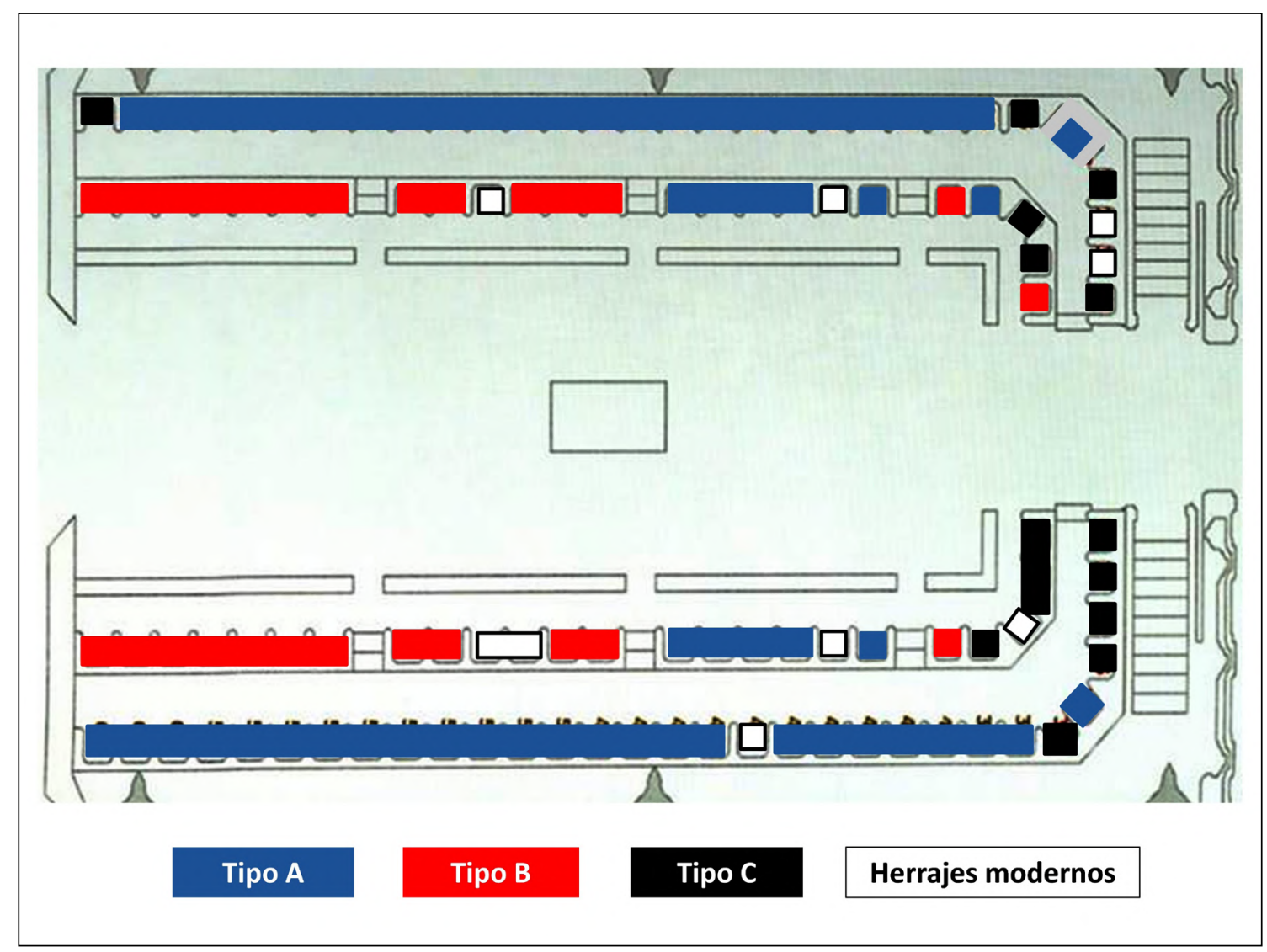

Fig. 3. Distribución de los diversos tipos de bisagras en la sillería del coro. Planta del coro extraída de L'Art Gòtic a Catalunya. Escultura II (Barcelona: Enciclopèdia Catalana, 2003), 42.

El proyecto quedó paralizado hasta mediados del siglo XV: en 1456, el capítulo catedralicio encargó a Macià Bonafè que dirigiese las obras de construcción de la sillería baja, destinada a los beneficiados. ${ }^{7}$ En 1459, los herreros Ramon Bertran y Antoni Mayans suministraron los clavos y Nestor Mateu hizo entrega de una segunda remesa en 1461. Las bisagras se encargaron a tres herreros distintos: Joan Ferrer ejecutó veintiocho pares de bisagras, que cobró el 18 de junio y el 15 de diciembre de 1459; Pere Caselles hizo otros dieciséis pares que se le remuneraron el 18 de abril de 1461. Y el 28 de mayo de 1463, se retribuían al herrero alemán, maestro Enric, treinta y una parejas de bisagras estañadas (vid. las transcripciones en el anexo).

La Guerra Civil catalana (1462-1472) paralizó el proyecto hasta 1483, fecha en que el maestro alemán, Miguel Lochner, recibió el encargo de terminar las obras que Bonafè había dejado inconclusas. La historiadora Montserrat Jardí apunta que el tramo ejecutado por Lochner, con la colaboración de su joven aprendiz Joan Frederic, correspondería a la sillería baja del trascoro. ${ }^{8}$ Sugiere también que la hilera alta del trascoro no se realizó hasta 1499. Este año se sustituyeron los antiguos sitiales románicos -maltrechos a causa de los destrozos efectuados durante la festividad de los Santos Inocentes de 1479por otros nuevos construidos por el carpintero mayor de la Catedral, Antoni Carbonell, y esculpidos por Juan Kassel, Daniel Rutart y Antoni Gomar. ${ }^{9}$ 
El 26 de julio de 1498, el cerrajero "de Megènia", ${ }^{10}$ Pere Riembau, cobraba seis libras, dieciséis sueldos y cuatro dineros por varios trabajos de cerrajería, entre los cuales se cuentan 'las bisagras de las sillas nuevas del coro' (vid. la transcripción en el anexo). La distribución de los herrajes confirma las atribuciones realizadas por los historiadores del arte en relación a la construcción de la sillería:

- Las bisagras del tipo A se concentran en los tramos ejecutados por Pere Sanglada y corresponderían a las piezas forjadas por Pascual Tarraga en 1398. Se encuentran también en el tercer tramo de la sillería baja, aunque en este caso resulta difícil atribuir autorías.

- Las bisagras de tipo B se concentran en los primeros tramos de la sillería baja. Su mayor riqueza decorativa, unida al hecho de que se conserven 26 parejas a las que hay que sumar otra misericordia desaparecida -y reconstruida modernamente-, me obliga a plantear si podrían corresponder a las ejecutadas por el maestro Enric en 1463. Recordemos que al maestro alemán se le retribuyeron un total de 31 pares y quizás su procedencia nórdica podría explicar la introducción de un nuevo diseño ornamental.

- Las bisagras de tipo C se concentran en las dos hileras del trascoro y corresponderían mayoritariamente a las forjadas por Pere Riembau en 1498, aunque también podrían relacionarse con la intervención de Lochner y su joven colaborador alemán en 1483. La presencia de bisagras de este tipo en la primera silla del coro, situada al lado de la del Obispo, se deba quizás a reparaciones modernas, aunque tenemos constancia de reformas en plena época medieval: el 24 de diciembre de 1491, el herrero Antoni Sureda cobró 3 sueldos y 4 dineros por "una pollagera de fferro per la cadira vella stà al costat de la cadira del sor bisba". ${ }^{11}$ Cabe señalar que la relación profesional entre Sureda y Pere Riembau era muy estrecha, ya que diversos registros consignados en los libros de obra califican a este último de "lochtinent d'en Anthoni Sureda". ${ }^{12}$

La presencia de artesanos franceses y alemanes en la Catedral de Barcelona, obliga a plantearse si hubo una posible influencia de modelos decorativos foráneos o, incluso, si los herrajes conservados en la sillería del coro pueden proceder de centros productores europeos. A partir de la documentación escrita y las comparaciones estilísticas, Maria Rosa Terés establece relaciones entre la sillería barcelonesa y la de la catedral de Chichester (v. 1315), aunque advierte que las semejanzas por sí solas nada revelan sobre las posibles vías concretas de trasmisión. ${ }^{13}$

Por otra parte, Licia Buttà atribuye a un taller vinculado a Bonafè la obra de la sillería de la catedral de Palermo (Sicília), realizada entre 1465 i $1467,{ }^{14}$ lo cual confirma el papel jugado por los artistas catalanes en la generación y transmisión de una especial configuración decorativa que se difunde durante los siglos XV y XVI por los territorios que se encuentran bajo el área de influencia de la corona catalanoaragonesa. Un estudio comparativo de los herrajes de la Catedral de Barcelona con los de sillerías similares, permitiría confirmar si existen también similitudes morfológicas y decorativas entre ellos. 


\section{Los herrajes de la librería del Arxiu de Mitja Escala}

La construcción de la librería del Arxiu de Mitja Escala se desarrolla en paralelo a la sillería baja del coro. El mueble es un armario de diversos cuerpos, provisto de arcones en su parte inferior, y adosado a tres de los muros que conforman el espacio.

El Arxiu de Mitja Escala se halla en el primer tramo de la escalera interior que comunica la capilla Bautismal, situada a los pies de la nave, con el primer triforio. Fue construido para guardar los pergaminos altomedievales que, a fines del siglo XIII, se compilaron en el cartulario conocido como Libri Antiquitatum. ${ }^{15}$

Entre los años 1432 y 1439, se documenta en los Libros de Obra de la Catedral de Barcelona la construcción de diversos elementos de carpintería y, entre septiembre de 1431 y marzo de 1432, se registra el aprovisionamiento de madera y clavos. El herrero Bernat Major ${ }^{16}$ y el mercader Pere de la Trinza -o Trinxa- ${ }^{17}$ suministraron diversas cantidades de clavos largos y del tipo barcherols, taulars y setials. El 17 de febrero de 1432 el carpintero mayor de la Catedral, Pere Blasco, recibía 20 sueldos por las jornadas de trabajo "qui ha obrat en la libraria", aunque la cita no permite identificar la naturaleza de esas labores. ${ }^{18}$ Paralelamente, se construía la puerta de madera que cerraba el espacio: el 10 de febrero de 1432, Bernat Major cobraba 5 sueldos por "IIII golfos spinosos, que ha mesos en las portas de la libraria nova" ${ }^{19}$ y el 9 de marzo de 1432 el cerrajero Pere Roqua cobraba 40 sueldos por "una loba, ab IIII claus, a la dita libraria, ab un bauló, que ha mes per tenir la porta, ab dos anells". ${ }^{20}$

El armario se construyó a lo largo del segundo semestre de $1439: 21 \mathrm{el}$ 20 de junio se documenta el pago de jornales a diversos carpinteros, entre los cuales se cuenta a Pere Blasco, aunque los registros no permiten confirmar si trabajaron en la librería. Ese mismo día se registra el pago de "II dotzenes de post de fulla de Solsona", de "mig cayrat per fer la fas del armari de la libraria", de "dues lates" y de diversos tipos de clavos al herrero Antoni Mayans. ${ }^{22}$ Un análisis a la madera que conforma el mueble permitiría identificar el tipo de árbol y confirmar si éste podría proceder de los bosques que en época medieval poblaron la actual comarca pre-pirenaica del Solsonès.

El 27 de junio se documentan más pagos por madera y el 24 de julio de 1439 Pere Blasco cobraba por "L punxes a obs de I armari de la libreria". ${ }^{23}$

El 22 de agosto de 1439, el herrero Joan Gilabert recibía 10 sueldos y 6 dineros por ocho bisagras y dos anillos destinados a las puertas de los armarios de la librería ${ }^{24}$ y el 24 de octubre cobraba nueve sueldos y seis dineros por dos cerrojos, cerraduras y llaves. ${ }^{25}$ Consta también que el 5 de diciembre de 1439 , el herrero Jaume Guavà percibió once sueldos por cambiar dos llaves y sus respectivas guardas. $^{26}$

La librería del Arxiu de Mitja Escala conserva los herrajes originales (fig. 4). ${ }^{27}$ Los cerrojos presentan una delicada decoración grabada a base de una retícula de dobles líneas, dispuestas en losange, que contienen un fondo punteado muy parecido al que decora los herrajes de tipo A de la sillería del coro. La cerradura, de cajetín y vértices prolongados en aguja, responde plenamente a la tipología gótica y existen paralelos en diversos muebles medievales. Valga 
como ejemplo el llamado 'cofre de la Reina' conservado en el mismo monasterio de Pedralbes, fechado en el siglo XIV (núm. inv. 115.088).

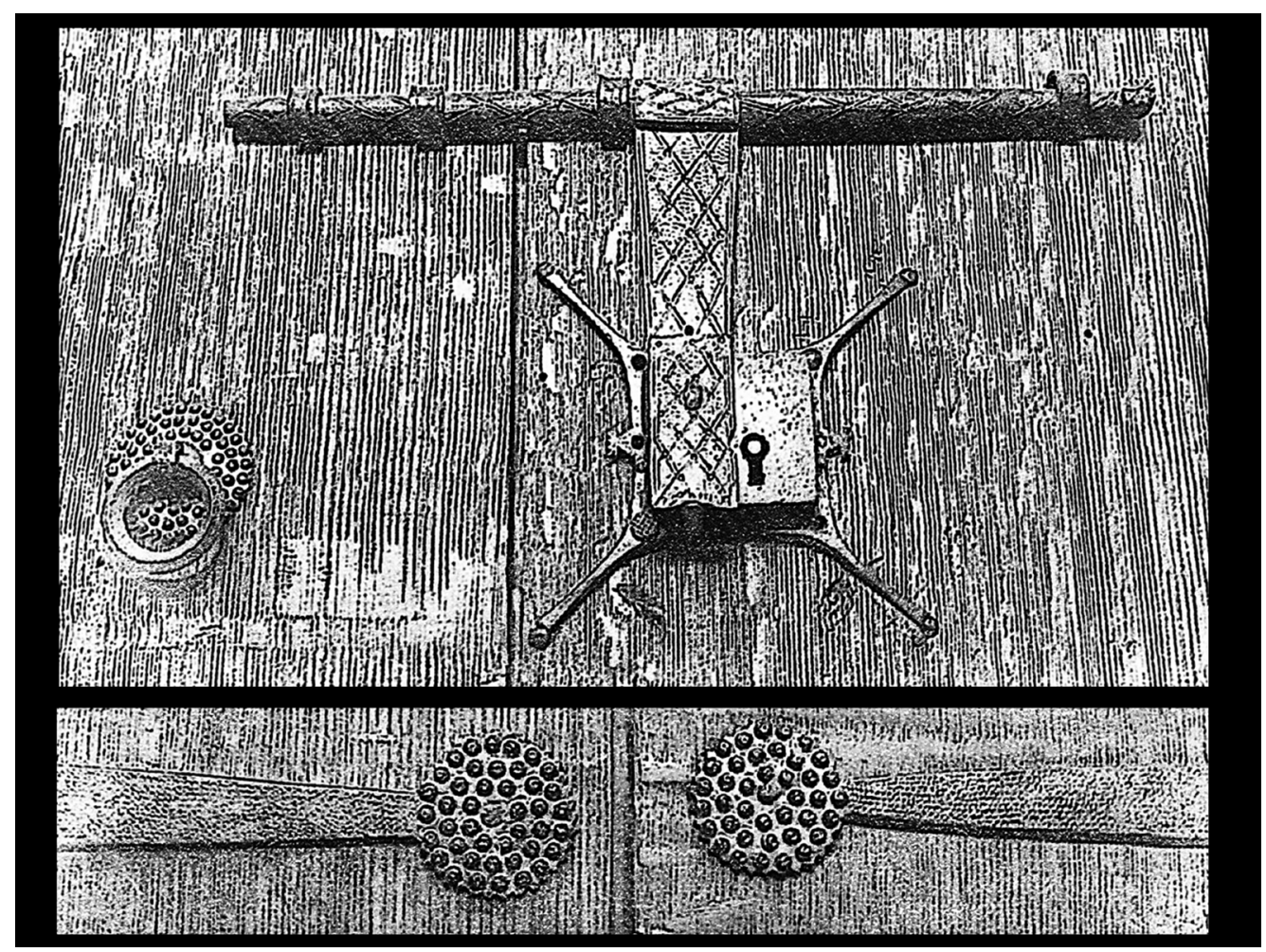

Fig. 4. Dibujo de los herrajes aplicados en la librería conservada en el Arxiu de Mitja Escala de la Catedral de Barcelona.

Las puertas del armario se articulan con charnelas de palas estilizadas cuyos tirantes, decorados con el mismo punteado que los cerrojos, terminan en unas expansiones circulares que contienen un repujado a base de pequeños motivos semiesféricos dispuestos en círculos concéntricos. Completan el conjunto unos sencillos tiradores de anilla provistos de escudetes iguales a los extremos de las palas.

La morfología y la decoración de los herrajes de esta librería son muy parecidos a los que presiden diversas puertas y muebles conservados en el monasterio de Pedralbes, fechados por la historiografía en el siglo XIV (fig. 5): cerrojos exactamente iguales a los de la librería de la Catedral cierran el denominado armario de la Reina y la puerta del dormitorio de las monjas (fig. 5-3 y 5-4); los mismos escudetes de tirador se aprecian en uno de los armarios de sacristía conservados en la clausura del monasterio, e iguales terminaciones circulares se observan en las palas de las charnelas de otro armario de sacristía (fig. 5-1a y 5 -2). ${ }^{28}$ Los tirantes de este último armario también presentan decoración cincelada pero, en este caso, los motivos son similares a los grabados en las bisagras del tipo B de la sillería baja del coro de la Catedral (fig. 5-1b). 


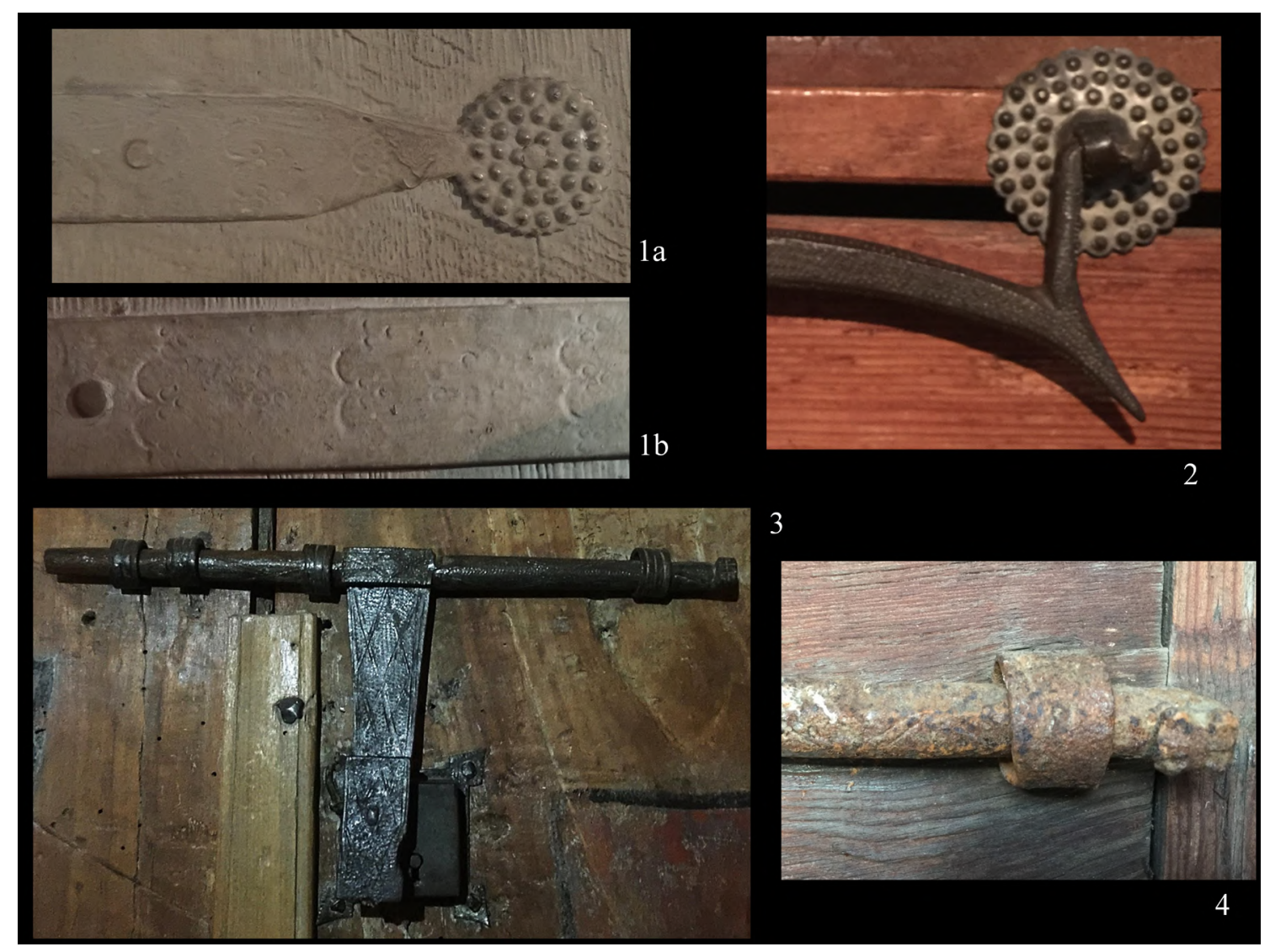

Fig. 5. Herrajes de muebles góticos del monasterio de Santa María de Pedralbes: 1/ Detalles de la pala de gozne del armario de sacristía núm. inv. 115.110. 2/ Tirador del armario de sacristía núm. inv. 115.108. 3/ Cerrojo del 'Armario de la Reina', núm. inv. 115.106. 4/ Extremo del cerrojo de la puerta del antiguo dormitorio de las monjas (Museu-Monestir de Pedralbes)

En el monasterio de Pedralbes se documentan tres de los artesanos que trabajaron en la construcción de la sillería del coro y la librería del Arxiu de Mitja Escala de la Catedral de Barcelona: el carpintero Pere Blasco y los herreros Bernat Major y Pere Caselles, aunque este último no podemos confirmarlo con seguridad. ${ }^{29}$ Pere Blasco fue carpintero mayor de la Catedral de Barcelona y, durante de década de 1420-1430, trabajó en colaboración con el herrero Bernat Major. Ambos se documentan también en Pedralbes entre 1419-1423, el primero, y 1419-1442, el segundo. ${ }^{30}$ Pere Blasco pertenecía a una estirpe de carpinteros barceloneses que realizaron numerosos trabajos en el monasterio de Pedralbes, aunque nosotros nos fijaremos sólo en los que conciernen a la fabricación de armarios: el 17 de julio de 1420, Domingo Blasco cobró por dos cerraduras y sus respectivas llaves destinadas a dos armarios, ${ }^{31} \mathrm{y}$ su hijo Vicenç construyó otros tantos armarios para el cenobio, entre los cuales destaca uno de sacristía pagado en el año $1430 .{ }^{32}$

Hasta el momento, no tenemos constancia documental de los cerrajeros que suministraron los herrajes para estos muebles. Cabe decir, no obstante, que carpinteros y herreros trabajaban en estrecha colaboración y a menudo eran los primeros quienes proveían de herrajes a sus clientes: el 1 de junio de 1432, el 
carpintero Ferrer Sunyer cobraba 8 dineros por "duas lantas de golfos" que instaló en la Catedral de Barcelona ${ }^{33}$ y el 11 de septiembre de 1431, el capítulo catedralicio ordenaba que se pagasen diversas piezas de hierro que los carpinteros Pere Blasco y Ferrer Sunyer habían sustraído del obrador del herrero Bernat Major. ${ }^{34}$ No era extraño, tampoco, que herreros y carpinteros se constituyesen en sociedades profesionales para satisfacer la demanda de productos concretos. Es el caso del herrero de Granollers, Alexandre Gober, y del carpintero barcelonés, Joan Bac, cuyos bienes se inventariaron el 26 de febrero de $1494 .^{35}$

A la luz de lo dicho, resulta evidente que existe una estrecha relación entre los muebles medievales conservados en la Catedral de Barcelona y en el monasterio de Pedralbes, lo que se explica por la actividad de unos artesanos que colaboraron a la vez con ambas instituciones religiosas. Aunque resulta arriesgado atribuir autoría a los armarios de sacristía de Pedralbes, no parece descabellado relacionarlos con los Blasco y sus colaboradores. De aceptar esta hipótesis, deberíamos retrasar su datación al intervalo cronológico en que documentamos su actividad, es decir, entre los años treinta y cuarenta del siglo XV.

\section{Conclusión y propuestas de estudio}

Las similitudes formales y morfológicas entre los herrajes conservados en la sillería del coro de la Catedral de Barcelona, la librería del Arxiu de Mitja Escala y los muebles del monasterio de Pedralbes tienen su denominador común en la actividad de unos artesanos que colaboraron con las dos instituciones.

No obstante, la presencia de artesanos franceses y alemanes en la obra de la sillería del coro de la Catedral, obliga a plantearse si hubo una posible influencia de modelos decorativos foráneos o, incluso, si algunos de los herrajes pueden proceder de centros productores europeos. Por contra, la transmisión al sur de Italia de los modelos morfológicos y decorativos emanados del coro barcelonés, abre nuevos interrogantes que sólo encontrarán respuesta impulsando estudios comparativos que permitan comprobar si también existen similitudes entre sus respectivos herrajes.

Un estudio de paralelos de este tipo debería tener en cuenta dos datos: que los herrajes de tipo $\mathrm{C}$ de la sillería del coro están relacionados con la actividad de artesanos alemanes y franceses, y que Barcelona mantuvo a lo largo de la baja Edad Media una dinámica actividad comercial con los territorios del mar del Norte, impulsada en buena medida por los mercaderes alemanes establecidos en la ciudad. ${ }^{36}$

Cataluña importaba productos de hierro procedentes del delta del Roine y de Niza, Génova y Milán. ${ }^{37}$ Estas manufacturas, entre las cuales se documentan clavos, cerrojos y cerraduras, llegaban a los puertos de Barcelona y Valencia por vía marítima y se redistribuían al mercado local a través de una dinámica red comercial articulada a través de los "botiguers de ferro" ${ }^{38}$

Cabe recordar, en este sentido, que las fuentes escritas catalanas registran herrajes procedentes de territorios europeos: en el inventario de la biblioteca del castillo de Peñíscola se relacionan «dos panys ffranceses la hu desguarnit». ${ }^{39}$ La cita permite suponer que existía un tipo de cerradura que los contemporáneos identificaban con producciones propias de los territorios galos. 
De entre los herreros documentados en la construcción del mobiliario de la Catedral, sólo Pere de la Trinxa puede relacionarse con los grandes mercaderes. ${ }^{40}$ En una súplica dirigida a los consejeros barceloneses, fechada en 1496, los herreros municipales solicitaron la exención del dret de penyora,${ }^{41}$ un abuso que aplicaban los mercaderes denominados Bonets y diversos botiguers de ferro de la ciudad. El documento cita a Pere de la Trinxa, a Bach, a Baruta y a Bonanat ferrer, y precisa que los Bonets acumulaban en sus almacenes un stock de más de dos mil quintales de hierro. ${ }^{42}$

Así pues, futuras líneas de investigación podrán confirmar si se trata de piezas de fabricación local o producciones más o menos seriadas importadas del mercado internacional, aunque las comparaciones que se hagan en este sentido conducirán sin duda a conclusiones interesantes más allá de la resolución de esta incógnita.

Sea como fuere, en el futuro sería necesario ampliar el trabajo histórico y completarlo con una documentación pormenorizada, que incluya estudios de paralelos y análisis metalúrgicos apropiados. Se trata, en definitiva, de analizar estas piezas en el marco de un proyecto más amplio, de carácter pluridisciplinar, que permita desentrañar los aspectos históricos, socioeconómicos, formales y tecnológicos que no hemos podido abordar en este estudio.

\section{Anexo}

PAGOS EFECTUADOS A HERREROS EN CONCEPTO DE HERRAJES DESTINADOS A LA SILLERÍA DEL CORO DE LA CATEDRAL DE BARCELONA

\begin{tabular}{|c|c|c|c|}
\hline FECHA & $\begin{array}{l}\text { RECEPTOR } \\
\text { DEL PAGO }\end{array}$ & $\begin{array}{c}\text { CONCEPTO } \\
\text { (TRANSCRIPCIÓN DE LA CITA) }\end{array}$ & $\begin{array}{c}\text { REFERENCIA } \\
\text { BIBLIOGRÁFICA }\end{array}$ \\
\hline 11 abril 1383 & $\begin{array}{l}\text { Berenguer Bertran, } \\
\text { ferrer }\end{array}$ & $\begin{array}{l}\text { Per C taulàs, los quals serviren de } \\
\text { clavar les posts del cor } \\
\text { Ítem, pagué per LXIIII sagetials, los } \\
\text { quals serviren a la dita faena } \\
\text { Ítem, li pagué per L berquerols, obs de } \\
\text { la dita faena }\end{array}$ & $\begin{array}{l}\text { AMENós 2005, }{ }^{43} \text { núm. } \\
955\end{array}$ \\
\hline 22 agosto 1394 & $\begin{array}{l}\mathrm{Al} \text { herrero (sin pre- } \\
\text { cisar nombre) }\end{array}$ & Qui féu V frencises & $\begin{array}{l}\text { TERÉs } 1987,{ }^{44} \text { p. } 105 ; \\
\text { AMENós } 2005 \text {, núm. } \\
1045\end{array}$ \\
\hline $\begin{array}{l}23 \text { diciembre } \\
1396\end{array}$ & $\mathrm{Al}$ herrero & $\begin{array}{l}\text { Pagui al farer que fa les frentises } \\
\text { dels sits }\end{array}$ & $\begin{array}{l}\text { TERÉs 1987, p. 111; } \\
\text { AMENós } 2005 \text {, } \\
\text { núm. } 1056\end{array}$ \\
\hline $\begin{array}{l}15 \text { diciembre } \\
1397\end{array}$ & Bernat Major, ferrer & $\begin{array}{l}\text { Galavernes per lo respatles } \\
\text { Claus }\end{array}$ & $\begin{array}{l}\text { TERÉs 1987, p. 114; } \\
\text { AMENós } 2005 \text {, } \\
\text { núm. } 1059\end{array}$ \\
\hline $\begin{array}{l}24 \text { diciembre } \\
1397\end{array}$ & $\begin{array}{l}\text { [Bernat] Major, } \\
\text { ferrer }\end{array}$ & Claus & TERÉs 1987, p.114 \\
\hline
\end{tabular}




\begin{tabular}{|c|c|c|c|}
\hline 5 enero 1398 & $\mathrm{Al}$ herrero & Pagui al farer qui fa las frentises & $\begin{array}{l}\text { TeRÉs 1987, p. 115; } \\
\text { AMENós } 2005 \text {, } \\
\text { núm. } 1060\end{array}$ \\
\hline " & $\mathrm{Al}$ herrero & $\begin{array}{l}\text { Pagui d'altre part al dit farer de les } \\
\text { frentises }\end{array}$ & $\begin{array}{l}\text { TeRÉs 1987, p. 115; } \\
\text { AMENós } 2005 \text {, } \\
\text { núm. } 106\end{array}$ \\
\hline 24 marzo 1398 & Bernat Major, ferrer & Claus de galavernes & $\begin{array}{l}\text { TERÉs } 1987, \text { p. } 116 \\
\text { AMENós } 2005 \text {, } \\
\text { núm. } 1062\end{array}$ \\
\hline 29 marzo 1398 & $\mathrm{Al}$ herrero & XXIIII fretises per los sitis & $\begin{array}{l}\text { TERÉs 1987, p. 116; } \\
\text { AMENós } 2005 \text {, } \\
\text { núm. } 1063\end{array}$ \\
\hline " & $\begin{array}{l}\text { Pascal Tarraga, } \\
\text { ferrer }\end{array}$ & Per les frentises & $\begin{array}{l}\text { TERÉs 1987, p. 119; } \\
\text { AMENós } 2005 \text {, } \\
\text { núm. } 1065\end{array}$ \\
\hline 15 febrero 1399 & Bernat Major, ferrer & Claus i galavernes & $\begin{array}{l}\text { TeRÉs 1987, p. 119; } \\
\text { AMENós } 2005 \text {, } \\
\text { núm. } 1066\end{array}$ \\
\hline
\end{tabular}

\begin{tabular}{|c|c|c|c|}
\hline FECHA & $\begin{array}{l}\text { RECEPTOR } \\
\text { DEL PAGO }\end{array}$ & $\begin{array}{c}\text { CONCEPTO } \\
\text { (TRANSCRIPCIÓN DE LA CITA) }\end{array}$ & $\begin{array}{c}\text { REFERENCIA } \\
\text { BIBLIOGRÁFICA }\end{array}$ \\
\hline 18 junio 1459 & Joan Ferrer, ferrer & $\begin{array}{l}\text { Per XIIII parells de francisses, a obs } \\
\text { de les cadires jusanes del cor, a rahó } \\
\text { de V sous lo parell }\end{array}$ & $\begin{array}{l}\text { JARDí } 2006, \text { p. } 122 \\
\text { AMENós } 2005, \text { núm. } \\
1068\end{array}$ \\
\hline 30 junio 1459 & $\begin{array}{l}\text { Ramon Bertran, } \\
\text { ferrer }\end{array}$ & $\begin{array}{l}\text { Un miller de claus sagetials, refets } \\
\text { un miller e cent claus taulars, refets, } \\
M^{i} C L \text { claus barquerols, a obs de les } \\
\text { cadires del cor }\end{array}$ & $\begin{array}{l}\text { AMENós } 2005 \text {, } \\
\text { núm. } 1069\end{array}$ \\
\hline 16 julio 1459 & $\begin{array}{l}\text { Anthoni Maihians, } \\
\text { ferrer }\end{array}$ & $\begin{array}{l}\text { CCCC claus barcarols } \\
\text { CCCC claus, punxes de fonar } \\
\text { CCCC claus, punxes d'enlistonar } \\
\text { (...) a obs de les cadires del cor jusà de } \\
\text { la Seu }\end{array}$ & $\begin{array}{l}\text { AMENÓs } 2005 \text {, } \\
\text { núm. } 1071\end{array}$ \\
\hline $\begin{array}{l}15 \text { diciembre } \\
1459\end{array}$ & Joan Ferrer, ferrer & $\begin{array}{l}\text { Per XIIII parells de francisses de } \\
\text { ferro, a obs de les cadires del cor jusa, } \\
\text { a rahó de V sous lo parell }\end{array}$ & $\begin{array}{l}\text { JARDí } 2006, \text { p. } 122 \\
\text { AMENós } 2005, \\
\text { núm. } 1078\end{array}$ \\
\hline
\end{tabular}




\begin{tabular}{|c|c|c|c|}
\hline 14 abril 1461 & $\begin{array}{l}\text { Anthoni Maihans, } \\
\text { ferrer }\end{array}$ & $\begin{array}{l}\text { XII claus ganxats } \\
\text { CCCC claus, punxes stanyades, } \\
\text { mil segitials, reforssats } \\
\text { mil taulars, reforssats } \\
\text { mil barquerols, reforssats } \\
\text { C dinals } \\
\text { CC mallals } \\
\text { CCC barquerols } \\
\text { CCC punxes de fonar } \\
\text { CCC punxes d'enlistonar } \\
\text { III rebols de ferro, (..) tot per obs de les } \\
\text { cadires del cor jusà }\end{array}$ & $\begin{array}{l}\text { AMENós } 2005, \\
\text { núm. } 1080 \\
\text { JARDí } 2006,{ }^{45} \text { p. } 123\end{array}$ \\
\hline 18 abril 1461 & Pere Caselles, ferrer & $\begin{array}{l}\text { XVI parells de francisses de ferro, per } \\
\text { obs de les cadires del cor jusà }\end{array}$ & $\begin{array}{l}\text { AMENÓs } 2005, \\
\text { núm. } 1081 \\
\text { JARDÍ } 2006, \text { p. } 124\end{array}$ \\
\hline 2 julio 1461 & $\begin{array}{l}\text { Nasthor Matheu, } \\
\text { ferrer }\end{array}$ & $\begin{array}{l}\text { C claus denals refets "a obs de les } \\
\text { cadires del cor } \\
L \text { mallals }\end{array}$ & JARDÍ 2006, p. 122 \\
\hline 28 mayo 1463 & $\begin{array}{l}\text { Mestre Enric, } \\
\text { farrer alemany }\end{array}$ & $\begin{array}{l}\text { XXXII parells de francisses } \\
\text { estanyades per obs de les cadires } \\
\text { del cor }\end{array}$ & $\begin{array}{l}\text { JARDí } 2006, \mathrm{p} .135 \\
\text { AMENós } 2005, \\
\text { núm. } 998 \\
\text { Amenós } 2007:^{46} 59 \text {, } \\
\text { nota núm. } 63\end{array}$ \\
\hline 5 enero 1477 & $\begin{array}{l}\text { [Antoni] Sureda, } \\
\text { ferrer }\end{array}$ & $\begin{array}{l}\text { Per fer una frantisa de un sitial, de } \\
\text { una cadira del cor maior }\end{array}$ & $\begin{array}{l}\text { AMENÓs } 2005, \\
\text { núm. } 1083 \\
\text { JARDÍ } 2006, \text { p. } 141\end{array}$ \\
\hline $\begin{array}{l}27 \text { noviembre } \\
1485\end{array}$ & $\begin{array}{l}\text { Rafael de } \\
\text { Casajussana, ferrer }\end{array}$ & $\begin{array}{l}\text { Per peraule del mestre fuster } \\
\text { Carbonell, donam en Raphell de } \\
\text { Cassejussane, ferrer, denou diners per } \\
\text { claus que d'él avie presos, per alguns } \\
\text { adobs de forats que havie devant les } \\
\text { cadires del cor major }\end{array}$ & $\begin{array}{l}\text { AMENós } 2005 \text {, } \\
\text { núm. } 1029\end{array}$ \\
\hline 4 julio 1487 & $\begin{array}{l}\text { Pere Riembau, } \\
\text { ferrer }\end{array}$ & $\begin{array}{l}\text { Per metre hun pern a una francissa de } \\
\text { las cadires canonicalls del cor }\end{array}$ & $\begin{array}{l}\text { AMENÓs } 2005, \\
\text { núm. } 1026 \\
\text { JARDí } 2006 \text {, p. } 193\end{array}$ \\
\hline $\begin{array}{l}24 \text { diciembre } \\
1491\end{array}$ & $\begin{array}{l}\text { Antoni Sureda, } \\
\text { ferrer }\end{array}$ & $\begin{array}{l}\text { Per una pollagera de fferro per la } \\
\text { cadira vella stà al costat de la cadira } \\
\text { del sor bisba }\end{array}$ & $\begin{array}{l}\text { AMENós } 2005 \text {, } \\
\text { núm. } 1035\end{array}$ \\
\hline
\end{tabular}




\begin{tabular}{|c|c|c|c|}
\hline 9 enero 1492 & $\begin{array}{l}\text { Antoni Sureda, } \\
\text { ferrer }\end{array}$ & $\begin{array}{l}\text { II gaffes de ferro, la una per antranar- } \\
\text { la ab un puntal ab la rexa del cor, } \\
\text { l'altra per antranar lo citial stà } \\
\text { devant l'ardiacha major }\end{array}$ & $\begin{array}{l}\text { AMENós } 2005 \text {, } \\
\text { núm. } 1036\end{array}$ \\
\hline 14 junio 1495 & Casajussana & $\begin{array}{l}\text { Per claus per hun faristol e per altres } \\
\text { cosses del cor }\end{array}$ & $\begin{array}{l}\text { JARDÍ } 2006, \\
\text { p. } 282-283 \\
\text { AMENÓs } 2005, \\
\text { núm. } 1108\end{array}$ \\
\hline 13 febrero 1498 & $\begin{array}{l}\text { Nadal Casajussana, } \\
\text { ferrer }\end{array}$ & $\begin{array}{l}\text { Per clavó, haven presa per los banchs } \\
\text { en torn lo cor... }\end{array}$ & $\begin{array}{l}\text { AMENós } 2005, \\
\text { núm. } 1091\end{array}$ \\
\hline 4 junio 1498 & Pere Rocha, ferrer & $\begin{array}{l}\text { Per dos pilars de ferro, e dos } \\
\text { guorniments de feristols, que serviren } \\
\text { per los feristols de les cadires noves }\end{array}$ & $\begin{array}{l}\text { AMENÓs } 2005, \\
\text { núm. } 1112\end{array}$ \\
\hline 26 julio 1498 & Pere Rianbau & $\begin{array}{l}\text { Per les francisses de les cadires noves } \\
\text { del cor }\end{array}$ & $\begin{array}{l}\text { JARDÍ } 2006, \\
\text { p. } 301-302 \\
\text { AMENÓs } 2005, \\
\text { núm. } 1092\end{array}$ \\
\hline 30 marzo 1499 & Pere Riembau & $\begin{array}{l}\text { Per francisses e tancadures, per les } \\
\text { portes del cor; e per qualsevol altre } \\
\text { ferramenta, so és, per les poliges de } \\
\text { ferro e altres ferrementes, hen servit } \\
\text { per les baranes del legender, }\end{array}$ & $\begin{array}{l}\text { AMENÓs } 2005, \\
\text { núm. } 947 \\
\text { JARDí } 2006 \text {, p. } 302\end{array}$ \\
\hline
\end{tabular}

\section{NOTAS}

${ }^{1}$ Aunque son perfectamente visibles en diversas fotografías antiguas del coro, destaco tres realizadas entre 1889 y 1914, donde se aprecian los facistoles con bastante detalle: Memòria Digital de Catalunya, Arxiu Fotogràfic del Centre Excursionista de Catalunya: AFCEC_XXX_ DV_005-00236,AFCEC_XXX_D_1644 y AFCEC_MORELLO_A_7581 [consultables en https:// mdc1.csuc.cat/].

${ }^{2}$ Lluïsa Amenós, "L'activitat dels ferrers a l'obra de la Seu de Barcelona entre el darrer terç del segle XIV i el segle XV," Estudis històrics i documents dels Arxius de Protocols 25 (2007), 61 y fig. p. 59. Santiago Rusiñol publicó un dibujo de la pieza en Àlbum de detalles artísticos y plástico-decorativos de la Edad Media Catalana (Barcelona: Imprenta de Luís Tasso y Sena, 1882), 37-38, fig. núm. 64.

${ }^{3}$ Amenós, "L'activitat dels ferrers," 60, fig. p. 57. Santiago Rusiñol publicó un dibujo de la pieza en Àlbum de detalles artísticos, 37-38, fig. núm. 64 bis.

${ }^{4}$ Amenós, "L'activitat dels ferrers," 69. Los candelabros -que cabría comprobar si se conservan-, son visibles en diversas fotografías anteriores a la Guerra Civil. Vid. por ejemplo la realizada en febrero de 1927 por el fotógrafo Josep Marimon (Archivo Nacional de Cataluña, ANC1-802-N-1630).

${ }^{5}$ Voravit Roothiva, El cor de la catedral de Barcelona. Aproximació als materials i a la tècnica constructiva del cadirat. Intervencions de restauració (Trabajo final de Máster, Universitat de Lleida, Facultat de Lletres, 2018), 67 y 127, fig. 47-48. Traducción al castellano: Lluïsa Amenós. ${ }^{6}$ M. Rosa Terés y Tomás, "Misericòrdies del cor de la Catedral de Barcelona," en Catalunya 1400. El gòtic internacional (Barcelona: Museu Nacional d'Art de Catalunya, 2012), 151-153; 
M. Rosa Terés y Tomás, "Pere Sanglada i l'arribada del gòtic internacional a Barcelona," en L'art gòtic a Catalunya: Escultura II (Barcelona: Enciclopèdia Catalana, 2003), 36-56; M. Rosa Terés y Tomás, Pere Ça Anglada. Introducció de l'estil Internacional en l'escultura catalana (Barcelona: Artestudi, 1987), 21-50; M. Rosa Terés y Tomás, "Pere Ça Anglada, maestro del coro de la catedral de Barcelona: Aspectos documentales y formales," D’Art 5 (1979), 51-64, figs. I-XII.

${ }^{7}$ Laura López Iborra, "Macià Bonafè i altres tallistes del segle XV," en L'art gòtic a Catalunya: Escultura II (Barcelona: Enciclopèdia Catalana, 2003), 195-196; M. Rosa Terés y Tomás, "Macià Bonafè y el coro de la Catedral de Barcelona. Nuevas consideraciones en torno a su intervención," Boletín del Museo e Instituto Camón Aznar 24 (1986), 65-85.

${ }^{8}$ Montserrat Jardí, Mestres entalladors a Barcelona durant la segona meitat del segle XV $i$ primer quart del segle XVI: de la tradició germànica a la producció local, vol. 1 (tesis doctoral, Universitat de Barcelona, 2006), 107-109.

${ }^{9}$ Jardí, Mestres entalladors, 155-158 y 164-172.

${ }^{10}$ Podría referirse quizás a la Mégénie (Departamento de Corrèze) en la región del Limousin. Sobre este topónimo, ver también Amenós, "L’activitat dels ferrers," 61, nota núm. 73.

${ }^{11}$ Archivo de la Catedral de Barcelona (ACB), Libro de Obra 1491-93, fol. 43.

${ }^{12}$ ACB, Libro de Obra, 1483-85(2), fol. 121.

${ }^{13}$ M. Rosa Terés y Tomás, "França o Anglaterra? Models per al cor de la catedral de Barcelona en època de Pere Sanglada," en Catalunya i l'Europa septentrional a l'entorn de 1400. Circulació de mestres, obres i models artístics (Roma: Viella editrice, 2016), 292.

${ }^{14}$ Licià Buttà, "Nicolau Pujades, il coro ligneo della Cattedrale di Palermo e alcune riflessioni sul viaggio di opere e artista catalani in Sicilia," en Capitula facta et firmata. Inquietuds en el quatre-cents, coord. M. Rosa Terés y Tomás (Valls: Cossetània Edicions y Universitat de Barcelona, 2011), 435-457.

${ }^{15}$ Diplomatari de l'Arxiu Capitular de la Catedral de Barcelona. Segle XI (Barcelona: Fundació Noguera, 2006), 22.

${ }^{16}$ El 23 de septiembre de 1431, se pagaron 1 sueldo y 9 dineros a "Bernat Major, farrer, per VI claus larchs, per la libraria" y el 7 de octubre, 1 sueldo y 6 dineros por clavos para la librería. ACB, Libro de Obra 1431-33, fol. 33-33v.

${ }^{17}$ ACB, Libro de Obra 1431-33, fol. 34 y 40.

${ }^{18}$ ACB, Libro de Obra 1431-33, fol. 38.

${ }^{19}$ ACB, Libro de Obra 1431-33, fol. 38.

${ }^{20}$ ACB, Libro de Obra 1431-33, fol. 39v.

${ }^{21} \mathrm{ACB}$, Libro de Obra. 1439-41, fol. 67, 71v, 78v y 75v.

22 "Ítem, mig cayrat per fer la fas del armari de la libraria: VI sous VI

Item, dues lates per lo dit armari: IIII sous

Ítem, per MC punxes, a rahó de XII diners lo cent: IIII sous

Ítem, per C barquerols per la dita libraria, a rahó de I sou: I sous, IV diners

Ítem, per C taulars per la dita libraria, a rahó de I sou, X diners lo cent: I sou, X diners

Item, a $n$ Mayans, ferrer, per XL aguts, de sutil: II sous

Ítem, per XII aguts, de bordet: VI diners". ACB, Libro de Obra 1439-41, fol. 67.

${ }^{23}$ ACB, Libro de Obra 1439-1441, fol. 67v y 69v

24 "Ítem més, pagam a $n$ Johan Gilabert, ferrer, per VIII ffrancisses e dos anells, qui serviren a les portes de la libraria e armaris, a rahó de I sou, III la peça de les ffrancisses, e a rahó de VIIII diners los anells: $X$ sous, VT'. ACB, Libro de Obra 1439-41, fol. 71v.

25 "Ítem, pagam a $n$ Johan Gilabert, ferrer, per II forreiats, ab panys e claus, qui serviren als armaris de la libraria: VIIII sous, VI diners". ACB, Libro de Obra 1439-41, fol. 75v.

26 "Ítem, a n Jacme Guavà, ferrer, per II claus lobes e les guardes, que muda en la tancadura de la libreria: XI sous." ACB, Libro de Obra 1439-41, fol. 78v. 
${ }^{27} \mathrm{El}$ metal de algunos de los herrajes requiere de un análisis metalúrgico para su correcta identificación.

${ }^{28}$ La madera de este último armario parece del mismo tipo que la de la librería del 'Arxiu de Mitja Escala' de la Catedral de Barcelona. Los armarios de Pedralbes citados en este estudio llevan los números de inventario 115.106, 115.108 y 115.110. Vid. Eva Pascual i Miró, "Els armaris," en L'Art Gòtic de Catalunya, vol. 8: Les arts de l'objecte (Barcelona: Enciclopèdia Catalana, 2008), 315-316; Mónica Piera i Miquel, "Armari capella, conegut com armari de la reina," en Petras Albas. El monestir de Pedralbes i els Montcada (1326-1673). Guia-Catàleg (Barcelona: Institut de Cultura, Museu d'Història de la Ciutat, Museu Monestir de Pedralbes, 2001), 8687, cat. núm. 6; Assumpta Escudero y Josep Mainar, El moble català al Monestir de Pedralbes (Barcelona: Ajuntament de Barcelona, Museu d'Art de Catalunya, 1976), 85 y fig. p. 50.

${ }^{29}$ Consta documentado que el 14 de julio de 1467 se retribuyó una cerradura y una llave de armario a un herrero llamado Caselles, que creemos identificar con Pere Caselles. Cristina Santjust i Latorre, L'obra del Reial Monestir de Santa Maria de Pedralbes des de la seva fundación fins al segle XVI (Tesis doctoral, Universitat Autònoma de Barcelona, 2008), 762.

${ }^{30}$ Latorre, L'obra del Reial Monestir, 752-753 y 782-783.

${ }^{31}$ Latorre, L'obra del Reial Monestir, 750.

${ }^{32}$ Latorre, L'obra del Reial Monestir, 754-756.

${ }^{33}$ ACB, Llibre d'Obra 1431-1433, fol. 78.

34 "Ítem, paguí de molt de temps passat a n Barnat Major, ferrer, que havien pres del seu obrador en Ferrer Sunyer e Pere Blascho, fustés, per IIII peus de golfos, nous, de peradar, qui pesaren XXIIII lliures e mige, obs del portal de la claustra nova". ACB, Llibre d'Obra 1431-32 [Claustre I], fol. 64 .

${ }^{35}$ Lluïsa Amenós, "L’ofici de ferrer a la Catalunya medieval," Butlletí Arqueològic 26 (2004), 203-204, doc. núm. 3.

${ }^{36}$ Claude Carrère, Barcelona 1380-1462. Un centre econòmic en època de crisi (Barcelona: Curial Documents de Cultura, 1977), vol. 1, 367-375 y vol. II, 48; Dolors Pifarré Torres, El Comerç internacional de Barcelona i el mar del Nord (Bruges) al final del segle XIV (Barcelona: Publicacions de l'Abadia de Montserrat, 2002); Máximo Diago Hernando, "Los mercaderes alemanes en los Reinos Hispanos durante los siglos bajomedievales: Actividad de las grandes Compañías en la Corona de Aragón," en España y el "Sacro Imperio» (Valladolid: Universidad de Valladolid, Secretariado de Publicaciones e Intercambio Editorial, 2002), 322-327.

${ }^{37}$ Carrère, Barcelona 1380-1462, 381-383.

${ }^{38}$ Lluïsa Amenós, "Ferramentes i proteccions dels vitralls d'època medieval (segles XIV-XVI)," en Els vitralls del monestir de Pedralbes i la seva restauració (Barcelona: Ajuntament de Barcelona, Institut de Cultura, 2011), 55.

${ }^{39}$ Manuel Betí, "Un Inventari del Castell de Penyiscola, any 1451," Estudis Universitaris Catalans. 8 (1914), 99.

${ }^{40}$ Lluïsa Amenós, "Catàleg de ferrers documentats en les fonts escrites d'època medieval," Butlletí Arqueològic 29 (2007), 124.

${ }^{41}$ Retención de una determinadacantidad dehierro, en concepto deempeño, hasta el pago final de una deuda contraída.

${ }^{42}$ Archivo Histórico de la Ciudad de Barcelona (AHCB), Gremis municipals, Ferrers 1460-1795: doc. año 1496.

${ }^{43}$ Lluïsa Amenós, L'activitat i les produccions dels ferrers en el marc de l'arquitectura religiosa catalana (segles XI-XV) (Barcelona: Universitat de Barcelona, 2005).

${ }^{44}$ Terés, Pere Ça Anglada, 105.

${ }^{45}$ Jardí, Mestres entalladors, 123.

${ }^{46}$ Amenós, "L’activitat dels ferrers," 59, nota núm. 63. 